\title{
Structural Characteristics of Composite Mortars and their Evolution with PET Substitution Level for Several Specimens' Ages
}

\author{
Kazi Tani N. ${ }^{1,4^{*}}$, Benosman A.S. ${ }^{1,2,3}$, Senhadji Y. ${ }^{3,5}$, Taïbi H. ${ }^{2}$, Mouli M. ${ }^{3}$
}

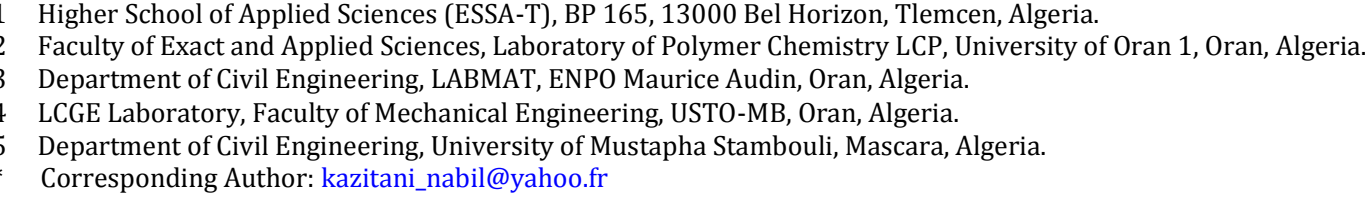

Received: 27-02-2018

Revised: 13-06-2018

Accepted: 14-06-2018

\begin{abstract}
This present study aims to investigate the evolution of structural response of PETMortar composite test with a short-beam specimen in three-point bending tests, with composite mortar ages and volumetric polymer rate and this, based on compression strength tests. The ultimate PET-mortar composite structural responses are calculated at the mid span of the short-beam by the mean of mechanics-of-materials theory basis. According to this theory, the distribution of bending moments and shear forces at any point of the composite short-beam specimen doesn't depend on material mechanical properties especially the young modulus of modified mortar composite; so, the structural response analysis has been limited to investigate the evolution of ultimate deflection with several volumetric PET rates and composite mortar ages. In the other hand, we present a comparative study between experimental test results of splitting tensile and compressive strengths with the ones predicted by codale previsions (ACI-363 and B.S) codes in terms of PET mortar ages and volumetric PET rates in order to recommend the most suitable design code for PET-mortar composite applications in construction industries.
\end{abstract}

Key words: Green Composites, Waste Polymer, Mortar Age, Young Modulus of elasticity, Three Point Flexural Test, Short-beam Lateral Deflections.

\section{Introduction}

The production of a large amount of Polyethylene Terephthalate (PET) bottles has created an environmental problem of gigantic proportions, since these bottles are not recycled by the manufacturers and therefore are left as plastic waste, which do not decompose readily in nature (Mahdi, 2007; Hannawi, 2010; Chowdhury, 2013).

The effective solution to solve this problem is to recycle them (Saikia, 2012; Ozbakkalogulu, 2016). Waste PET bottles had been reworked for drinking bottles by melting and fusion, which turned out to be too costly. The incorporation of PET waste in construction materials knows a very high evolution in the last couple years, and this due to the significant economic impact of this green materials used in construction industries where polymers are used as additives (Sharma, 2016; Pacheco, 2013) in order to reduce certain disadvantages such as hardening delay, low tensile strength, and the general drying shrinkage (Yazoghli, 2007).

Actually, composite materials (Yazoghli, 2007; Benazzouk, 2007; Cordoba, 2013; Naik, 1996) are by now the subject of both theoretical and experimental investigations, motivated by a renewed interest for the use of polymer-mortar composites in the civil construction industry for different applications (Cordoba, 2013; Naik, 1996; Benosman, 2015, 2017a,b). So, if waste PET bottles were reused as lightweight aggregates, positive effects are expected on the recycling of waste resources and the protection of the environment (Ozbakkalogulu, 2016; Sharma, 2016; Ochi, 2007; de Brito, 2013; Kazi Tani, 2017; Gouasmi, 2017). Considerable research and 
development work on plastic waste modification for cement mortar and concrete has been conducted in various countries. As a result, many effective plastic waste modification systems for cement mortar have been used in various applications in the construction industry for its many excellent properties (Latroch, 2018; Chaib, 2017; Ozbakkalogulu, 2016; Sharma, 2016; de Brito, 2013; Batayneh, 2007; Choi, 2005; Rebeiz, 1996). These researches generally investigate the effect of incorporating PET waste on the properties of concrete and cementitious mortar.

Commonly, the results showed that granules or flakes of crushed PET post-consumer bottles can be used to replace sand to produce good quality concrete products. On the other hand, our previous work (Benosman, 2008, 2013, 2015, 2017a) indicated that PET waste could reduce the apparent chloride ion diffusion coefficient of the composites, effectively enhance the reduced volume of large-sized pores and improve the resistance to the absorption of the test solutions (like acidic, basic, sulfatic solutions) as well as the thermal resistance and acoustic insulation with an increase in polymer-cement ratio. This current study concentrates on the waste materials without any further transformation beyond crushing, in order to minimize final material costs.

Certain key proportions are also studied, in contrast with what has been undertaken in previous work (Benazzouk, 2007; Benosman, 2011, 2015; Ghernouti, 2012; Safi, 2013; Badache, 2018) in order to determine feasibility limits. Particularly PET wastes are used as substitute for conventional materials, mainly cement as powder, in composites mixes. So, the main purpose of this present research work is to characterize in the first time the mechanical properties of this composite mortar for several PET-Mortar ages and volumetric waste PET polymer rates in accordance to (ACI-318) and (BS-8110) codes of practice and based on experimental compressive strength tests results.

The second stage of this work consists to investigate the flexural behavior of modified PETMortar specimen under three-point bending-tests in terms of elastic deflections based on predicted data base of experimental test results.

The last part of this paper concerns the evolution analysis of tensile and compressive strength $(\mathrm{Ft} / \mathrm{Fc})$ ratio with early mortar ages and volumetric PET rates between experimental test results and predicted ratios suggested by the British Code of Practice BS-8007:1987 (BSI, 1987) and the ACI-363 models (ACI, 1992), in the aim to direct designers and researchers to the most suitable code for PET-mortar composite applications in the field of construction industries.

\section{Raw materials}

\subsection{Cement}

The cement used was a blended Portland cement type CPJ-CEM II/A42.5 supplied by Zahana factory, located in western Algeria, with $1022 \mathrm{~kg} / \mathrm{m}^{3}$ bulk density; its compressive strength at 28 days was $42.5 \mathrm{MPa}$. The absolute density of the cement used was $3.15 \mathrm{~g} / \mathrm{cm}^{3}$ and its specific surface area measured with the Blaine method was $3532 \mathrm{~cm}^{2} / g$. Its initial and final setting times were 170 and $245 \mathrm{~min}$, respectively. Mineralogical and chemical compositions of cement are listed in Table 1. The chemical composition was obtained using an X-ray fluorescence spectrometer.

\subsection{Sand}

The crushed natural limestone sand was obtained from the quarry of Kristel, in Oran, West Algeria. The maximum size of sand grains was $5 \mathrm{~mm}$. The chemical properties shown in Table 1 were obtained by using an X-ray fluorescence spectrometer analysis. Its principal characteristics are given in Table 2. The grading of crushed sand is presented in Table 3, according to standard NF P18-560 (AFNOR, 1990). 
Table 1. The mineralogical compositions of clinker and the chemical compositions of cement and sand used (wt. \%)

\begin{tabular}{|c|c|c|c|}
\hline \multirow{12}{*}{$\begin{array}{c}\text { Chemical } \\
\text { compositions }\end{array}$} & Constituent & Cement & Sand \\
\hline & $\overline{\mathrm{SiO}_{2}}$ & 20.91 & 0.77 \\
\hline & $\mathrm{Al}_{2} \mathrm{O}_{3}$ & 5.52 & 0.11 \\
\hline & $\mathrm{Fe}_{2} \mathrm{O}_{3}$ & 3.56 & 0.36 \\
\hline & $\mathrm{CaO}$ & 63.50 & 54.71 \\
\hline & $\mathrm{MgO}$ & 0.64 & 0.21 \\
\hline & $\mathrm{SO}_{3}$ & 2.79 & Nil \\
\hline & $\mathrm{K}_{2} \mathrm{O}$ & 1.23 & - \\
\hline & $\mathrm{Na}_{2} \mathrm{O}$ & 0.13 & - \\
\hline & CaO free & 2.35 & - \\
\hline & Chlorides & - & Nil \\
\hline & LOI & 1.19 & 43.83 \\
\hline \multirow{4}{*}{$\begin{array}{l}\text { Mineralogical } \\
\text { compositions }\end{array}$} & $\mathrm{C}_{3} \mathrm{~S}$ & 49.39 & - \\
\hline & $\mathrm{C}_{2} \mathrm{~S}$ & 22.97 & - \\
\hline & $\mathrm{C}_{3} \mathrm{~A}$ & 8.61 & - \\
\hline & $\mathrm{C}_{4} \mathrm{AF}$ & 10.83 & - \\
\hline
\end{tabular}

Table 2. Physical properties of sand used (Benosman, 2011)

\begin{tabular}{|l|l|}
\hline Designations & Values \\
\hline \hline Absolute density $\left(\mathrm{g} / \mathrm{cm}^{3}\right)$ & 2.53 \\
\hline Equivalent of Sand $(\%)$ & 84 \\
\hline Fineness modulus & 2.55 \\
\hline Nature & Limestone \\
\hline Absorption coefficient (\%) & 0.5 \\
\hline
\end{tabular}

\subsection{PET waste}

Waste PET bottle granules (Scheme 1) used as particles were supplied by TRAMAPLAST PET Bottle Plant, in Tlemcen, Algeria. These particles were obtained by collecting the waste PET bottles and washing them; they are then crushed by granules into machines. In addition, they have an irregular shape and a rough texture surface, which enables the adherence of the particle-matrix. The bulk density of the waste PET particles used was $401.4 \mathrm{~kg} / \mathrm{m}^{3}$.

After preliminary tests, PET waste particles of size lower than $1 \mathrm{~mm}$ were used in this study. The sieve analysis of PET waste particles was carried out according to standard NF P18-560 (AFNOR, 1990) and is presented in Table 3.

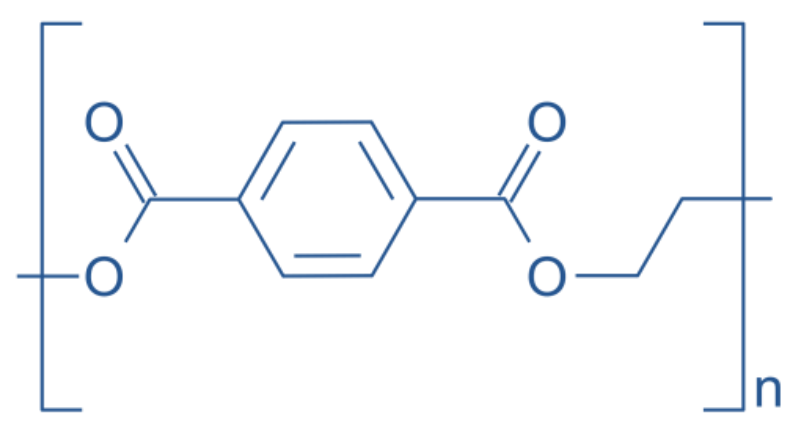

Scheme 1. Developed chemical formula of Waste Polyethylene Terephthalate 
Table 3. The sieve analysis of waste PET-Particles and crushed limestone sand (Kazi Tani, 2017)

\begin{tabular}{|c|c|c|}
\hline \multirow{2}{*}{ Sieve size $(\mathrm{mm})$} & \multicolumn{2}{|c|}{ Cumulative passing (\%) } \\
\cline { 2 - 3 } & PET Waste & Sand \\
\hline \hline 5 & 99.92 & 99.83 \\
\hline 2.5 & 98.16 & 98.37 \\
\hline 1.25 & 96.82 & 65.37 \\
\hline 0.63 & 55.78 & 38.3 \\
\hline 0.315 & 35.48 & 19.07 \\
\hline 0.16 & 18.28 & 8.20 \\
\hline 0.125 & 9.56 & 3.325 \\
\hline
\end{tabular}

\section{Specimen preparation and experimental tests}

Four PET-mortar composites mixtures were prepared to compare the effect of adding PET as a cement replacement material. First, the control sample was without PET waste. The other three polymer-mortar composite mixtures were made by replacing cement with $6 \%, 12 \%$, and $17 \%$ of PET by volume as shown in Table 4 . The mortar mixes had proportions of 1 binder: 3 Sand (by weight). The binder consisted of cement and PET waste. The water to binder ratio was kept constant at 0.5 . The physical properties of the pastes of mortars were determined in accordance with EN 196-3 (EN196-3, 1995). The detailed mix proportions of the mortars are shown in Table 4. For the mechanical properties, the compressive strength of mortars was determined in accordance with EN 196-1 (EN 196-1, 1995). The mortar was placed in 40x40x160 $\mathrm{mm}^{3}$ prismatic steel molds. After casting, specimens were left covered with a plastic sheet. After removal from the molds, at $24 \mathrm{~h}$ of age, mortar specimens were immersed in water saturated with lime at $20^{\circ} \mathrm{C} \pm 2{ }^{\circ} \mathrm{C}$ until the age of testing. Compression and three point bending tests Figure. 1 were conducted at $3,7,14,28,56,90,180$ and 360 days of age. The results reported are the average of three flexural specimens and six compression tests.

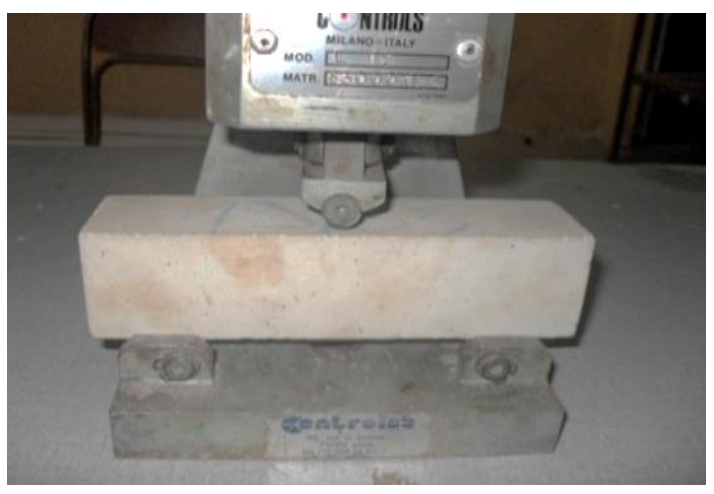

Fig 1. Three point bending test equipment

Table 4. Mix proportions and physical properties of PET-mortar composites

\begin{tabular}{|c|c|c|c|c|c|c|}
\hline $\begin{array}{c}\text { Mix } \\
\text { design }\end{array}$ & $\begin{array}{c}\text { PET/C } \\
\left(\%^{\mathrm{v}}\right)\end{array}$ & $\begin{array}{c}\text { Binder: Sand (by } \\
\text { weight) }\end{array}$ & $\begin{array}{c}\text { Water-Cement } \\
\text { ratio }(\%)\end{array}$ & $\begin{array}{c}\text { Water demand for } \\
\text { Standard }(\%)\end{array}$ & $\begin{array}{c}\text { Setting Time } \\
(\mathrm{min})\end{array}$ \\
\hline \hline$/$ & $/$ & $/$ & $/$ & $/$ & Initial & Final \\
\hline PET 0 & 0 & $1: 3$ & 50 & 24.5 & 120 & 200 \\
\hline PET 6 & 6 & $1: 3$ & 50 & 25 & 125 & 205 \\
\hline PET 12 & 12 & $1: 3$ & 50 & 25.5 & 130 & 210 \\
\hline PET 17 & 17 & $1: 3$ & 50 & 26 & 145 & 225 \\
\hline
\end{tabular}




\section{Results and discussion}

\subsection{Mechanical characterization of PET-Mortar Composites}

The static modulus of elasticity E (Young Modulus) represents one of the most important mechanical characteristics of construction materials (Concrete, Reinforced concrete, mortars, composites ...etc.). This intrinsic property is considering as the basic parameter for the computing deflections in construction structures. Various countries have been established their design codes based on empirical relationship between static modulus of elasticity $\mathrm{E}$, and compressive strength of plain concrete at 28 days of curing.

(a)

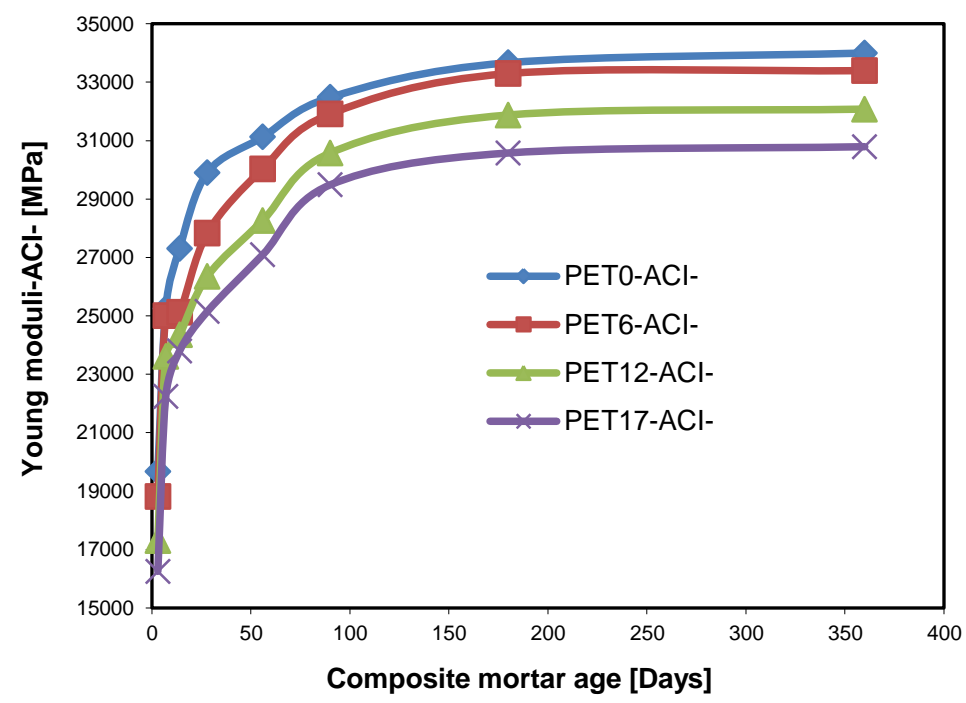

(b)

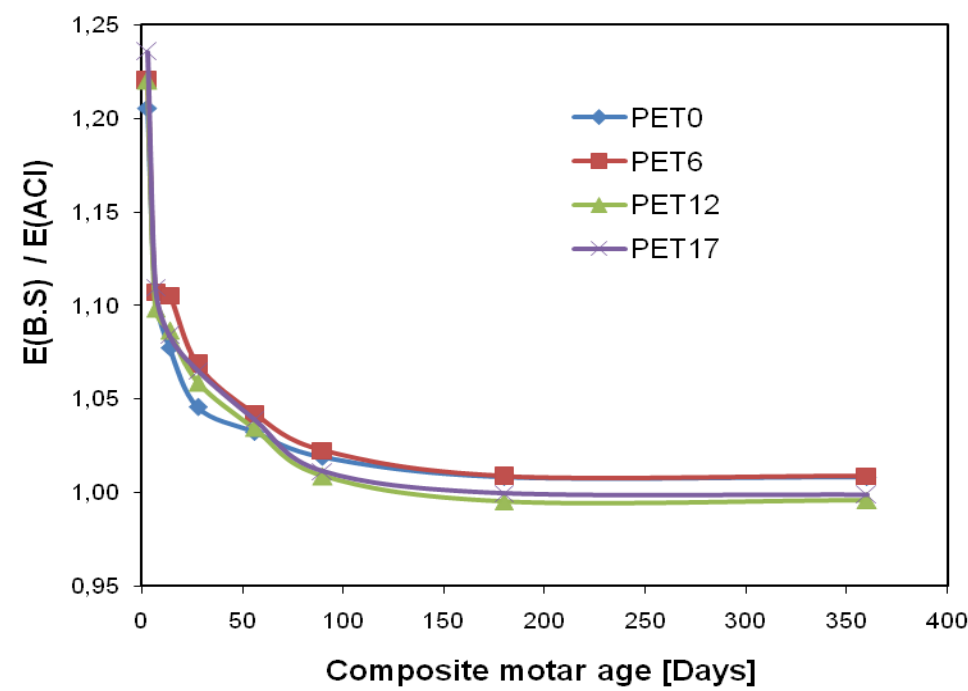

Fig 2. Evolution of Young modulus with volumetric PET rate and composite mortar ages via (a) ACI-318 and (b) BS-8110 codes.

The ACI code (ACI-318, 2005) defines the relationship between elastic modulus of concrete and compressive strength for calculating deflection as:

$E_{C}=w^{1.5} \cdot 0,043 \cdot \sqrt{f_{c}}$

The British Code of practice (BS-8110, 1997) recommends the following expression for static modulus of elasticity with cube compressive strength of concrete as: 
$E_{C}=w^{2} \cdot 0,0017 \cdot f_{c}^{0.33}$

Where

Ec: The static modulus of elasticity (E) at 28 days in MPa

fc: Compressive strength at 28 days in $\mathrm{MPa}$

w: Air dry density of mortar

Based on experimental compressive tests on PET-Mortar composite specimens (Benosman, 2011), and there densities, graphs in figures 2(a)-2(b) show the evolution of Young modulus evaluated by empirical relationships in accordance to (ACI-318, 2005) and (BS-8110, 1997) codes.

The graphs plotted in the figures 2(a)-2(b) show that the Elastic Young Modulus values predicted by The British Code of practice (BS-8110) are in the higher side comparing them with the ones evaluated by (ACI-318) code and this, for all studies cases regarding volumetric PET rates and mortar ages. In order to have an accurate prediction of the Elastic Young Modulus of PET-Mortar Composite which is very important for structures and that required a strict control of deformability. International codes such as ACI-318 and BS-8110 propose a wide variety of formulae which establish a relationship between modulus of elasticity and compressive strength.

\subsection{Flexural strain analysis}

As shown in Figure 3, which illustrates three points bending test method, the PET-mortar composite specimen is supported by the reaction noses and the load $\mathrm{P}$ is applied at a constant speed through the loading nose. The stress and strain fields at any point in the short-beam section can be evaluated to a first approximation with mechanics-of-materials theory. This theory is based on the necessary conditions for static equilibrium, which pertains here because the rate of deformation is small.

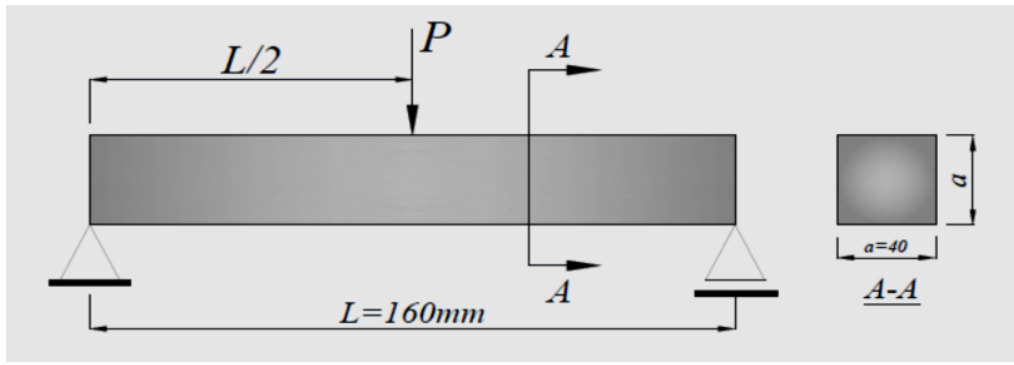

Fig 3. Three-point-bending test on PET-Mortar Composite specimens $(40 \times 40 \times 160) \mathrm{mm}^{3}$

The basic assumptions of the theory are as follows:

- $\quad$ The external forces are applied at thin lines and not distributed over finite areas.

- $\quad \sigma_{\mathrm{y}}=\sigma_{\mathrm{z}}=0\left(\sigma_{\mathrm{y}}\right.$ and $\sigma_{\mathrm{z}}$ are the transverse normal stresses).

- $\sigma_{\mathrm{x}}=\mathrm{E} \varepsilon \mathrm{x}$ (where $\sigma_{\mathrm{x}}$ is the longitudinal normal stress and $\mathrm{E}$ the elastic Young modulus).

- $\quad \tau_{\mathrm{xy}}=0,\left(\tau_{\mathrm{xy}}\right.$ is the in-plane shear stress $)$.

After the equilibrium conditions are applied for stresses $\sigma_{\mathrm{x}}$ and $\tau_{\mathrm{xz}}$ these two major components of the stress can be obtained.

$\sigma_{\mathrm{x}}$ has its maximum tensile or compressive value at the lower or upper point of the specimen:

$\sigma_{\mathrm{x}}=\frac{3 \mathrm{PL}}{2 \mathrm{bt}^{2}}$ 
Where $\mathrm{P}$ is the load and $\mathrm{b}$ is the width of the specimen. According to the Euler-Bernoulli theory, the maximum elastic deflection arising from a flexural stress in a rectangular beam $\delta_{\max }$ is:

$\delta_{\max }=\frac{3 P L^{3}}{48 E I}$

Where, I denotes the moment of inertia of the specimen section.

In the following, we present a parametric study which can allow us to investigate the effect of waste PET additions in the construction mortars in terms of flexibility and flexural strain evolution.

Figures 4(a)- 4(b) bellow show the evolution of ultimate deflections computed by (ACI-318) and (BS-8110) codes with composite mortar ages and this for different volumetric polymer rates. The obtained simulation results show that the most significant values of ultimate PET shortbeam specimen composite deflections are given when Young modulus is evaluated by (ACI-318) code, especially where composite mortar ages vary between 3 and 28 days. At long term of PETmodified mortar ages, the results of ultimate beam responses seems the same for both evaluation cases of Young modulus by (ACI-318) and (BS-8110) codes.

The volumetric rate of waste PET polymer has a significant impact of the flexural behavior of PET-composite mortar and this for short and long term of composite mortar ages. The increased rate of Polyethylene Terephthalate gives to composite mortar specimen more flexibility and then, PET-Mortar composite became more ductile before to be brittle for the case of ordinary mortar.

Finally, it is important to notice that under the action of the same loads which correspond to the tensile strength of PET-mortar composite specimen, the highest volumetric rate of PET increases the values of ultimate deflection for both evaluation cases of Young modulus by (ACI-318) and (BS-8110) codes.

The utilization of the PET waste as a binder instead of cement in the manufacture of such composites and as sustainable building materials in the construction industry helps to cleaner environment. Therefore, the substitution of cement by the PET polymer waste is beneficial for energy efficiency and sustainability in buildings.

(a)

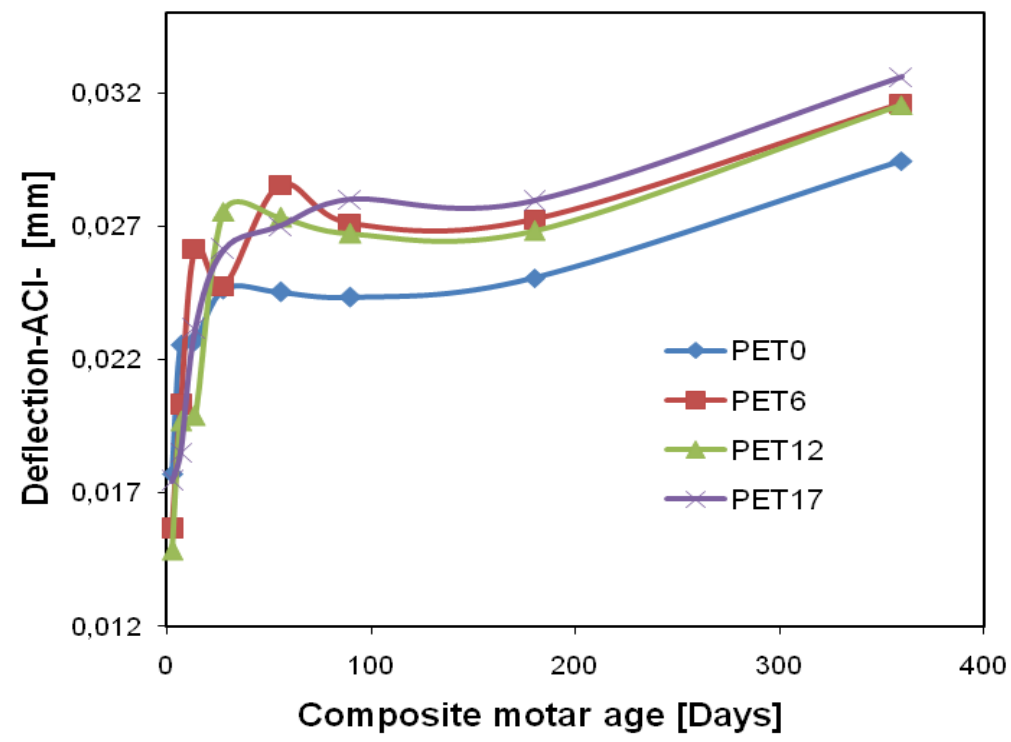


(b)

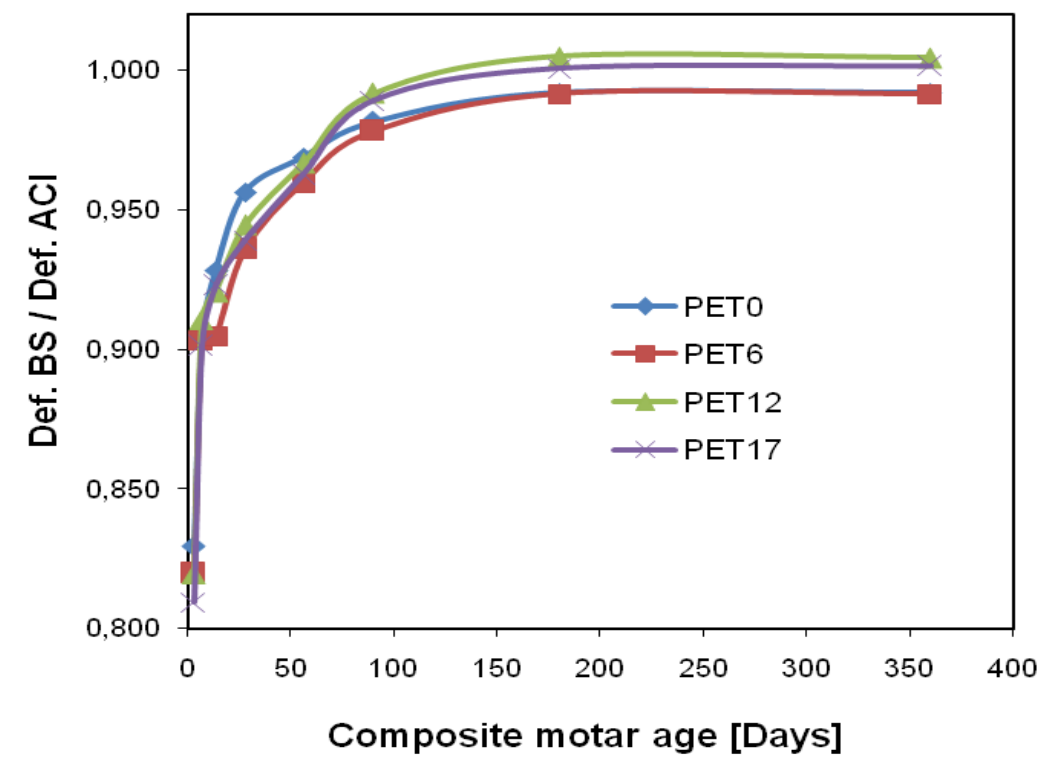

Fig 4. Evolution of short-beam specimen ultimate deflections with volumetric PET rate and composite mortar ages: (a) ACI-318 and (b) BS-8110 codes.

\subsection{Splitting tensile and compressive strengths ratio (Ft/Fc)}

The ratio between tensile and compressive strength $(\mathrm{Ft} / \mathrm{Fc})$ is an important material property of mortars and concrete. In this section, we investigate the evolution of the $(\mathrm{Ft} / \mathrm{Fc})$ ratio between splitting tensile strength and compressive strength with volumetric PET rate and early PETmortar composite ages (07 and 28 days) and this, based on experimental test results (Benosman, 2011). In the other hand, we present a comparative study between the experimental evaluation of splitting tensile strength and compressive strength ratio (Ft/Fc) and the predicted ratios given by the British Code of Practice (BS-8007,1987) and the (ACI-363, 1992) models respectively as follows:

$\begin{aligned} F_{t} & =0,12 \cdot F_{c}{ }^{0.7} \\ F_{t} & =0,56 \cdot F_{c}{ }^{0.5}\end{aligned}$

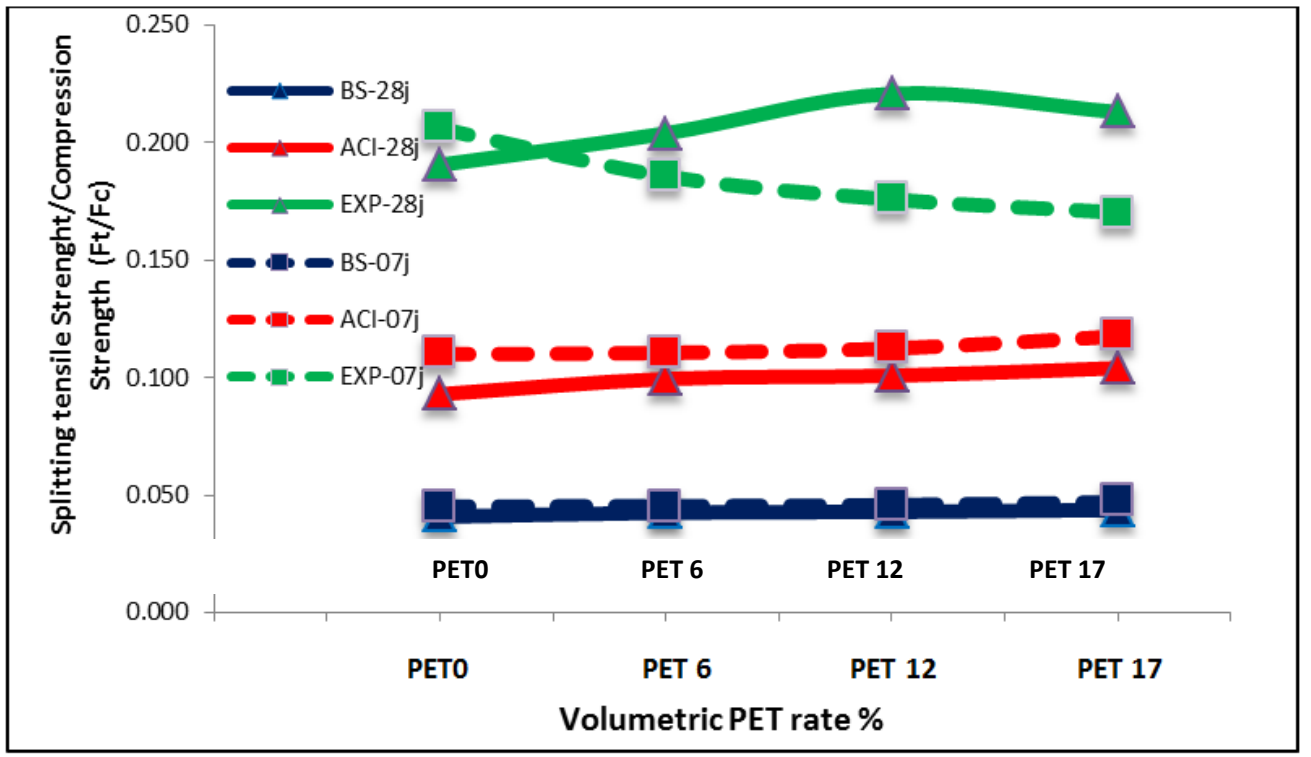

Fig 5. Evolution of $\left(F_{t} / F_{c}\right)$ with volumetric PET rates for 7 and 28 days short-beam 
The graphs plotted in the figure 5 above show that $(\mathrm{Ft} / \mathrm{Fc})$ ratio follow an increased slight evolution with volumetric PET rates and this ratio became more significant at early age of PETmortar composite (7 days) for the case of codal prediction. Predicted ratio between tensile and compressive strength (Ft/Fc) suggested by ACI-363 code is closer to the experimental (Ft/Fc) ratio. This prediction seems to be more realistic if we compare it to the model given by British Standard code of practices BS-8007:1987. Therefore, ACI-363 code can be considered as the most suitable for the prediction of mechanical properties of PET-mortar composite material in its several applications in the field of construction industry.

\section{Conclusion}

This study of semi-experimentally obtained mechanical properties of PET mortar composites and its flexural strain analysis, led the following main conclusions:

- $\quad$ The experimental measured values of compression and flexural strength of PET mortar composite specimen can be useful to predict the elastic Young modulus through the corresponding codal previsions (ACI-318 and BS-8110 codes). For all the mortar composite ages, the prediction of BS-8110 code values is in higher side compare with predicted Young modulus values given by ACI-318 code.

- $\quad$ For all the studied cases, the PET volumetric rates have a significant effect of the mechanical properties of PET-Mortar composite especially at the long term mortar age where Young elastic modulus decreases significantly with the increasing PET volumetric rates of the composite mortar regardless of the code prevision (ACI-318 and BS-8110).

- $\quad$ Flexural strain analysis of PET-Mortar composite show that the incorporation of PET wastes in the mortar give more flexibility of PET-Mortar composite, especially when the PET volumetric rate is relatively higher (\%PET= 12 and 17). This can be explained by the increasing of the ultimate deflection specimen with PET volumetric rate and mortar ages.

- Unlike the case of Young modulus codal prediction, predicted ratio between tensile and compressive strength $(\mathrm{Ft} / \mathrm{Fc})$ given by $\mathrm{ACI}-363$ code are closer to the $(\mathrm{Ft} / \mathrm{Fc})$ ratio evaluated by experimental test results. For all studied cases, the volumetric PET rates have a slight effect on $(\mathrm{Ft} / \mathrm{Fc})$ ratio especially at early age of PET-mortar composites.

In this way, the obtained PET waste modified mortars would appear to be low-cost composite materials which would contribute to resolving some of the solid waste problems in addition to conserving energy.

\section{Acknowledgements}

The authors acknowledge financial support from the Ministry of Higher Education and Scientific Research of Algeria, under the grants CNEPRU B00L01UN310120130068. The authors would like to thank the anonymous referees for improving the quality of this manuscript.

\section{References}

ACI 318. (2005). Building Code Requirements for Structural Concrete (ACI 318-05) and Commentary (ACI 318R-05). ACI Committee 318, American Concrete Institute, Farmington Hills, MI.

ACI Committee 363. (1992). State-of-the-Art Report on High-Strength concrete (ACI 363R-92). American Concrete Institute, Farmington Hills, Mich.

AFNOR, (1990). Granulats. Analyse Granulométrique par Tamisage. NFP 18-560, Association française de normalisation. 
Badache, A., Benosman, A.S., Senhadji, Y., \& Mouli, M. (2018). Thermo-physical and Mechanical Characteristics of Sand-Based Lightweight Composite Mortars with Recycled High-Density Polyethylene (HDPE), Construction and Building Materials, 163, 40-52.

Batayneh, M., Iqbal, M., \& Ibrahim, A. (2007).Use of selected waste materials in concrete mixes, Waste Management, 27, 1870-1876.

Benazzouk, A., Douzane, O., Langlet, T., Mezreb, K., Roucoult, J.M., \& Quéneudec, M. (2007). Physicomechanical properties and water absorption of cement composite containing shredded rubber wastes, Cement \& Concrete Composites, 29, 732-740.

Benosman, A.S., Mouli, M., Taibi, H., Belbachir, M., \& Senhadji, Y. (2011). Resistance of Polymer (PET) Mortar Composites to Aggressive Solutions, International Journal of Engineering Research in Africa, 5, 1-15.

Benosman, A.S., Mouli, M., Taibi, H., Belbachir, M., Senhadji, Y., Bahlouli, I., \& Houivet, D. (2013). Studies on Chemical Resistance of PET-Mortar Composites: Microstructure and Phase Composition Changes, Engineering, 5(4), 359-378.

Benosman, A.S., Mouli, M., Taibi, H., Belbachir, M., Senhadji, Y., Bahlouli, I., \& Houivet, D. (2017a). The chemical, mechanical and thermal properties of PET-Mortar composites containing waste PET. Environmental Engineering and Management Journal (EEMJ), 16(7), 1489-1505.

Benosman, A.S., Senhadji, Y., \& Mouli, M. (2015). Application of Polymer-Mortar Composites as a Sustainable Building Material, Key Engineering Materials, 650, 21-28.

Benosman, A.S., Taibi, H., Mouli, M., Belbachir, M., Senhadji, Y. (2008). Diffusion of Chloride Ions in Polymer-Mortar Composites, Journal of Applied Polymer Science, 110, 1600-1605.

Benosman, A.S., Taibi, H., Mouli, M., Senhadji, Y., Belbachir, M., Bahlouli, I., \& Houivet, D. (2015). Effect of addition of PET on the mechanical performance of PET-Mortar Composite materials. Journal of Materials and Environmental Science, 6 (2), 559-571.

Benosman, A.S., Taïbi, H., Senhadji, Y., Mouli, M., Belbachir, M., Bahlouli, M.I. (2017b). Plastic Waste Particles in Mortar Composites: Sulfate Resistance and Thermal Coefficients. Progress in Rubber Plastics and Recycling Technology Journal, RAPRA, SMITHERS, 33(3), 171-202.

BS 8110. (1997). Structural use of concrete. Code of practice for design and construction. British Standards Institution.

BSI. (1987). BS 8007: 1987 Code of practice for design of concrete structures for retaining aqueous liquids. London: BSI.

Chaib, O., Benosman, A.S., Kazi Tani, N., Senhadji, Y., Mouli, M., Taïbi, H., \& Hamadache, M. (2017). The Evolution of Shrinkage Strain of PET-Mortar Composite Eco-Materials, Journal of Fundamental and Applied Sciences (JFAS), 9(1), 136-152.

Choi, Y.W., Moon, D.J., Chung, J.S., \& Cho, S.K. (2005). Effects of waste PET bottles aggregate on properties of concrete, Cement and Concrete Research, 35, 776-781.

Chowdhury, S., Maniar, A.T., \& Suganya, O. (2013). Polyethylene terephthalate (PET) waste as building solution. Int. J. Chem. Environ. Biol. Sci. (IJCEBS), 1, 2320-4087.

Cordoba, L.A., Berrera, G.M., Diaz, C.B., Nunez, F.U., \& Yanez, A.L. (2013). Effects on mechanical properties of recycled PET in cement-based composites. International Journal of Polymer Science, 1-6.

de Brito, J., \& Saikia, N. (2013). Recycled Aggregate in Concrete; Use of an Industrial, Construction and Demolition Waste. (Eds.), Springer, London Heidelberg New York Dordrecht, pp. 431.

EN 196-1. (1995). Methods of testing cement - Part 1: determination of strength. Comité Européen de Normalisation (CEN).

EN 196-3. (1995). Methods of testing cement - Part 3: determination of setting time and soundness. Comité Européen de Normalisation (CEN).

Ghernouti, Y., \& Rabehi, B. (2012). Strength and Durability of Mortar Made with Plastics Bag Waste (MPBW), International Journal of Concrete Structures and Materials, 6(3), 145-153. 
Gouasmi, M.T., Benosman, A.S., \& Taïbi, H. (2017). Development of Materials Based on PET-Siliceous Sand Composite Aggregates. Journal of Building Materials and Structures, 4(2), 58-67

Hannawi, K., Kamali-Bernard, S., \& Prince, W. (2010). Physical and mechanical properties of mortars containing PET and PC waste aggregates. Waste Management, 30, 2312-2320.

Kazi Tani, N., Benosman, A.S., Senhadji, Y., Taïbi, H., \& Mouli, M. (2017). Mechanical Strengths of Modified PET Mortar Composites in Aggressive $\mathrm{MgSO}_{4}$ Medium: ACI \& B.S Predictions. Journal of Building Materials and Structures, 4(2), 76-83.

Latroch, N., Benosman, A.S., Bouhamou, N.-E., Senhadji, Y., Mouli, M. (2018). Physico-mechanical and Thermal Properties of Composite Mortars Containing Lightweight Aggregates of Expanded Polyvinyl Chloride. Construction and Building Materials, 175, 77-87.

Mahdi, F., Khan, A.A., \& Abbas, H. (2007). Physiochemical properties of polymer mortar composites using resins derived from post-consumer PET bottles. Cement and Concrete Composites, 29, 241-248.

Naik, T.R., Singh, S.S., Huber, C.O., \& Brodersen, B.S. (1996). Use of post-consumer waste plastic in cementbased composites. Cement and Concrete Research, 26, 1489-1492.

Ochi, T., Okubo, S., \& Fukui, K. (2007). Development of recycled PET fiber and its application as concretereinforcing fiber. Cement and Concrete Composites, 29, 448-455.

Ozbakkaloglu, L., \& Gu, T. (2016). Use of recycled plastics in concrete: A critical review. Waste Management, 51, 19-42.

Pacheco, T.F., \& Ding, Y. (2013). Concrete with polymeric wastes, Eco-Efficient Concrete, A volume in Woodhead Publishing Series in Civil and Structural Engineering, Book Chapter 13, ed. by: F. Pacheco-Torgal, S. Jalali, J. Labrincha and V. M. John, 311-339.

Rebeiz, K.S. (1996). Precast use of polymer concrete using unsaturated resin based on recycled PET waste, Construction and Building Materials, 10, 215-220.

Safi, B., Saidi, M., Aboutaleb D., \& Maallem, M. (2013). The use of plastic waste as fine aggregate in the selfcompacting mortars: Effect on physical and mechanical properties. Construction and Building Materials, 43, 436-442.

Saikia, N., \& de Brito, J. (2012). Use of plastic waste as aggregate in cement mortar and concrete preparation: A review. Construction and Building Materials, 34, 385-401.

Sharma, R., \& Bansal, P. P. (2016). Use of different forms of waste plastic in concrete - a review. Journal of Cleaner Production 112, 473-482.

Yazoghli-Marzouk O., Dheilly, RM., \& Quéneudec, M. (2007). Valorisation of post-consumer waste plastic in cementitious concrete composites. Waste Management, 27, 310-318. 